\title{
Influence of recrystallization annealing regime on the formation of a fine-grained structure in structural steels
}

\author{
Valeriy Gordienko ${ }^{1, *}$, Alexandr Chernykh ${ }^{1}$, and Sergei Repin ${ }^{1}$ \\ ${ }^{1}$ Saint Petersburg State University of Architecture and Civil Engineering, 2 Krasnoarmejskaja ul.4, \\ Saint Petersburg, 190005, Russia
}

\begin{abstract}
The analysis of the main factors affecting the reliability and safety of welded metal structures in long-term operation is carried out. The features of obtaining a fine-grained structure due to recrystallization annealing and the main factors affecting the degree of dispersion of the formed microstructure are considered. For low-carbon steel 08ps and lowalloy steel 09G2S, optimal recrystallization annealing regimes have been developed with the aim of obtaining final structures with a given degree of dispersion, typical for real building metal structures. It was found that the degree of dispersion of the obtained microstructures depends on the heating temperature, the initial structure, and the chemical composition of the steels.
\end{abstract}

\section{Introduction}

Reliable and safe operation of welded metal structures (MS) of industrial buildings, structures and construction equipment can be largely ensured by the correct and timely technical diagnostics using modern methods, techniques and monitoring tools at all stages of the life cycle: manufacturing, installation, long-term operation [1-5]. However, in many cases, structural steel used in the manufacture of welded metal structures does not allow safe operation from the point of view of brittle fractures of elements of construction metal structures [6]. One of such examples is the collapse of a 30-meter secondary truss and roof trusses of charge holding bay and furnace bay resting on it at an air temperature of $-30{ }^{\circ} \mathrm{C}$ in the building of the electric steelmaking workshop of OMZ Spetsstal (OMZ-Special Steels LLC) in Kolpino, Leningrad Region.

The causes of destruction of welded metal structures often include the presence of structural, mechanical and chemical heterogeneity in welded joints, high residual stresses, the occurrence of dangerous local zones of stress concentration, the identification of which is difficult due to the insignificance of their size. Considering the fact that the structure determines the mechanical properties of the metal, its changes during operation, the observed structural heterogeneity in various elements of metal structures and in welded joints (cast structure in the welded seam, coarse-grained structure in the overheating zone,

* Corresponding author: repinserge@mail.ru 
fine-grained structure in the recrystallization section) have a significant impact on the performance characteristics of the structure as a whole, especially in adverse operating conditions.

The imperfection of existing diagnostic methods, tools and techniques, the need for thorough preparation of the control surface [7, 8] allow concluding that a comprehensive approach, which includes the development and exploitation of promising materials and methods for their processing, as well as application of effective technologies strengthening metal alloys can help solve the problem of diagnosing a technical condition [9-11].

Recently, there has been a tendency to intensify a number of physicochemical processes through the use of the nature of various materials and the phase and structural transformations occurring in them. Thus, the most important characteristics of construction steels that are responsible for long-term operation at low temperatures include the temperature of transition from a viscous to a brittle state, which largely depends on the initial microstructure of the elements of metal structures, since with decreasing grain size, impact strength and ductility of metal at low temperatures increase [12].

It is known that metals with a body-centered cubic lattice (BCC) have a tendency to transition from a viscous to a brittle state at low temperatures. As a result, steels operating at a temperature below the brittle temperature are fractured without the formation of a neck. This type of destruction is most dangerous, since destruction occurs by an avalanche-like mechanism. It should be emphasized that the impact strength is significantly affected by the initial grain size.

\section{Materials and Methods}

The studies were carried out on samples of 08ps and 09G2S steels, which were subjected to fractional cold plastic deformation with subsequent recrystallization annealing. The study was carried out using metallographic analysis. Metallographic analysis was carried out using a set of tools, including grinding and metallographic equipment. Carl Zeiss Axio Observer and Liica DMJ 5000 inverted metallographic microscopes with mechanized tables equipped with Thixomet quantitative image analysis systems were chosen for metallographic studies. In preparing the micro sections, a four percent solution of nitric acid in ethanol was used. The grain size was determined by the secant method (Glagolev method). Recrystallization annealing of the studied samples was carried out in programmable muffle furnaces with microprocessor control.

\section{Results and Discussion}

Thus, studies [13] showed that when the grain size of steel Jn-744 changes from 2 to 25 $\mu \mathrm{m}$, the temperature of transition from viscous to brittle fracture changes toward higher temperatures from $-130{ }^{\circ} \mathrm{C}$ to $-45^{\circ} \mathrm{C}$. Moreover, the difference in mechanical properties was caused only by a decrease in grain size, since the chemical composition of the phases of fine-grained and coarse-grained metal was the same.

Considering that the structural state determines the properties of metals and alloys, it was of scientific and practical interest to trace the formation of the fine-grained structure of structural steels depending on the impact of various factors on it. An analysis of a number of scientific works showed that one of the most acceptable methods for obtaining a structure with a different degree of dispersion in low-carbon and low alloy steels is recrystallization annealing. To select the optimal regime for such annealing, it is necessary to consider the features of recrystallization processes in metals and alloys based on them. It should be borne in mind that recrystallization is divided into primary (recrystallization of 
processing) and secondary (collective) [14]. Primary recrystallization allows us to completely remove the hardening created by plastic deformation, and to form a fine-grained structure. After its completion, subsequent heating of the metal leads to the growth of some recrystallized grains due to other neighboring ones - this is secondary recrystallization. Moreover, a large number of small grains and a small number of very large ones can be observed in the structure. The process of growth of recrystallized grains is called collective recrystallization, its driving force is the desire of the system to reduce free energy. A larger grain has a smaller total grain surface, and, therefore, a smaller supply of free energy than two separate ones. The increase in grain size is diffusive due to the gradual attachment of atoms of vanishing grains to the lattice of the growing grain. During recrystallization, the heating temperature is not a constant physical quantity. It depends on such factors as the degree of cold plastic deformation, the duration of heating, the initial grain size before deformation. The recrystallization temperature is the lower, the greater the degree of preliminary plastic deformation, the greater the grain size before deformation and the duration of heating.

The size of the grains after recrystallization can be both larger and smaller than the initial grain, since the formation of the structure during annealing depends on many factors. Such factors include not only the temperature of recrystallization annealing (Fig. 1, a), but also the duration of heating (Fig. 1, b), the degree of preliminary plastic deformation (Fig. $1, c)$, the initial grain size, the chemical composition of the alloy, fragmentation of plastic deformation, the presence of various insoluble impurities.



temperature

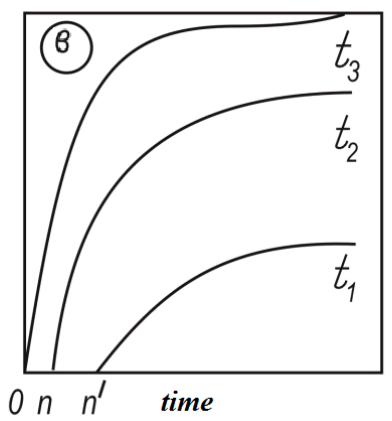

$0 \cap n^{\prime}$ time



degree of deformation

Fig. 1. The effect of temperature (a), heating time (b) and degree of deformation (c) on the grain size after recrystallization $(\mathrm{t} 1<\mathrm{t} 2<\mathrm{t} 3)$.

Thus, with an increase in the annealing temperature and an increase in its duration at the same degree of preliminary deformation, the value of recrystallized grains increases (Fig. 1, $a, b)$. At the same time, the greater the degree of plastic deformation, the smaller the size of the recrystallized grains. This is explained by the fact that with an increase in the degree of deformation, the number of areas with an increased dislocation density increases, as a result of which the possibility of the formation of new recrystallization centers increases. Therefore, with significant degrees of plastic deformation, the rate of appearance of recrystallization nuclei exceeds their growth rate, which contributes to the formation of a fine-grained structure.

With a decrease in the initial grain size (at the same degree of deformation), a finergrained structure is formed [15]. The faster the rate of metal heating to a given temperature, the finer the recrystallized grains [16]. Fractional cold plastic deformation also contributes to a more dispersed structure. 
All of these factors were taken into account in this work both during cold plastic deformation and when choosing the temperature of recrystallization annealing and holding time.

Low-carbon steel 08ps and low-alloy steel 09G2S were chosen for scientific research. They were chosen due to the following facts:

- $\quad$ steels have good ductility characteristics;

- $\quad$ are widely used in construction and other industries;

- $\quad$ have different strength categories;

- make it possible to disseminate the obtained patterns and issue sound recommendations on steels similar to the studied ones in terms of their composition and mechanical properties.

The chemical composition of the studied steels is shown in table. 1

Table. 1. The chemical composition of the studied steels is shown.

\begin{tabular}{|l|c|c|c|c|c|c|}
\hline \multirow{2}{*}{ Steel } & \multicolumn{5}{|c|}{ Chemical composition, \% } \\
\cline { 2 - 8 } & \multirow{2}{*}{$\mathrm{C}$} & $\mathrm{Mn}$ & $\mathrm{Si}$ & $\mathrm{Al}$ & $\mathrm{P}$ & $\mathrm{S}$ \\
\hline 08ps & & & & & & \\
\hline 09G2S & 0.06 & 0.27 & 0.05 & 0.0011 & 0.019 & 0.022 \\
\hline
\end{tabular}

Samples from 08ps and 09G2S steels as received were subjected to fractional cold plastic deformation by a strain degree of $\varepsilon=50 \%$, followed by recrystallization annealing. Recrystallization annealing was carried out in the temperature range of $20 \ldots 900{ }^{\circ} \mathrm{C}$ (up to $600{ }^{\circ} \mathrm{C}$ every $150{ }^{\circ} \mathrm{C}$, from $600{ }^{\circ} \mathrm{C}$ to $900{ }^{\circ} \mathrm{C}$ every $25^{\circ} \mathrm{C}$ ) with a two-minute exposure in an oven and subsequent cooling in water. The formation of a fine-grained structure was controlled using metallographic analysis. Metallographic analysis was carried out by a set of instruments, including grinding and metallographic equipment.

Grinding equipment included:

- $\quad$ unit for precise cutting - Brilliant 220;

- $\quad$ unit for mounting - Opal 460;

- unit for grinding and polishing - Saphir 560.

Carl Zeiss Axio Observer and Lieica DMJ 5000 inverted metallographic microscopes with mechanized tables equipped with Thixomet quantitative image analysis systems were chosen for metallographic studies. The use of these devices allows solving numerous problems associated with qualitative and quantitative metallographic analysis. In preparing microsections, a four percent solution of nitric acid in ethanol was used. The grain size was determined by the secant method (Glagolev method) [16] according to the results of 5-9 measurements with an increase in $x 650$. Research data were processed mathematically.

Recrystallization annealing of the studied samples was carried out in programmable muffle furnaces with microprocessor control SNOL 8.2/1100.

The data of metallographic studies showed that the temperature of the onset of recrystallization for steel $08 \mathrm{ps}$ was $550{ }^{\circ} \mathrm{C}$, for steel $09 \mathrm{G} 2 \mathrm{~S}-600^{\circ} \mathrm{C}$, the temperature of the end of recrystallization for steel $08 \mathrm{ps}$ was $700{ }^{\circ} \mathrm{C}$ and for steel $09 \mathrm{G} 2 \mathrm{~S}-725^{\circ} \mathrm{C}$. During primary recrystallization, a fine-grained structure is formed: in steel $08 \mathrm{ps}$, the grain size is 8 microns, in 09G2S - 6 microns (Fig. 2, 3). An increase in the annealing temperature led to a significant increase in grain size. The smallest grain size and the smallest grain growth was observed in the low alloy steel 09G2S in comparison with the low carbon steel 08ps, which gives a stabilizing effect on the structure of finely dispersed particles of the carbide phase in this steel. 


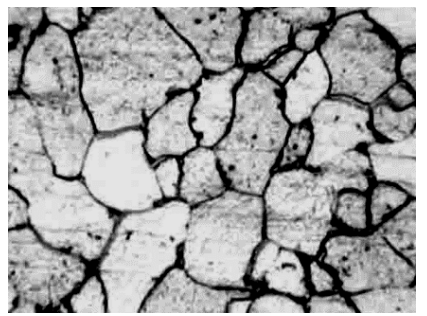

a

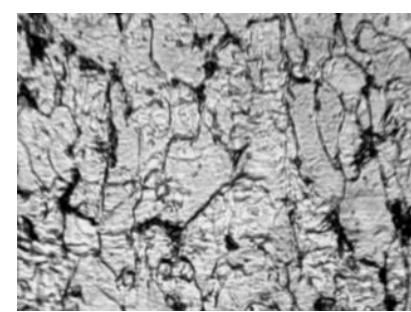

$\mathrm{b}$

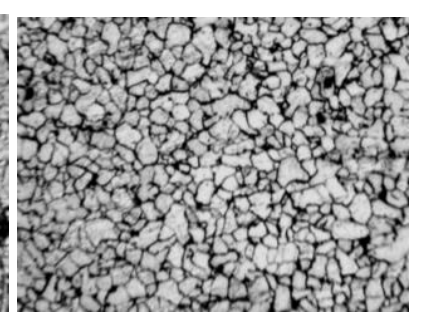

c

Fig. 2. Change in the structure of steel 08ps during recrystallization annealing, x650: as received $(a)$, after rolling by $\varepsilon=50 \%(b)$, after rolling by $\varepsilon=50 \%$ and annealing at $700{ }^{\circ} \mathrm{C}(\mathrm{c})$

Thus, according to the research results, it can be concluded that, fixing a rather early stage of completion of primary recrystallization in steels $08 \mathrm{ps}$ and $09 \mathrm{G} 2 \mathrm{~S}$, it becomes possible to obtain a fine-grained structure, which is formed even more fine-grained for steel 09G2S, which has alloying elements in its composition.

An increase in the annealing temperature leads to the passage of secondary and collective recrystallization, which results in the formation of a more equilibrium structure with increased different grain size and larger than the initial one, which is very important for obtaining coarse-grained structures when modeling various structural states of structural steels.
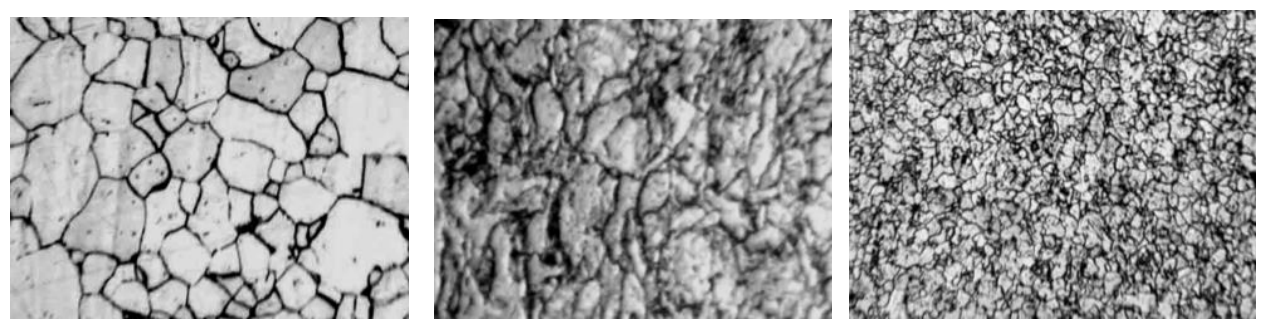

Fig. 3. Change in the structure of steel $09 \mathrm{G} 2 \mathrm{~S}$ during recrystallization annealing, $\mathrm{x} 650$ : as received (a), after rolling by $\mathcal{E}=50 \%(b)$, after rolling by $\mathcal{E}=50 \%$ and annealing at $725^{\circ} \mathrm{C}(\mathrm{c})$

\section{Conclusions}

1. The main factors affecting the production of a fine-grained structure in structural steels during recrystallization annealing are considered: temperature, speed and duration of metal heating, fractionality and degree of cold plastic deformation, initial grain size, chemical composition of steels, and the presence of various insoluble impurities.

2.It has been established that, regardless of the initial structure and chemical composition of low-carbon steel 08ps and low-alloy steel09G2S, a structure with varying degrees of dispersion is formed during recrystallization annealing, which is typical for real welded construction metal structures.

3. The finest-grained structure with a grain size of $8 \mu \mathrm{m}$ in steel $08 \mathrm{ps}$ and $6 \mu \mathrm{m}$ in steel $09 \mathrm{G} 2 \mathrm{~S}$ is formed at a heating temperature of $700{ }^{\circ} \mathrm{C}$ and $725^{\circ} \mathrm{C}$, respectively. Obtaining a more dispersed structure in steel $09 \mathrm{G} 2 \mathrm{~S}$ can be associated with a stabilizing effect on the formed structure of finely dispersed particles of the carbide phase in this steel.

4.It was found that the degree of dispersion of the obtained microstructures after recrystallization annealing depends on the heating temperature, the initial structure, and the chemical composition of the steels. 


\section{References}

1. V.E. Gordienko (SPbGASU. - SPb., 2004)

2. V. E. Gordienko (SPbGASU. - SPb., 2010)

3. V. E. Gordienko (SPbGASU. - SPb., 2011)

4. V. E.Gordienko (SPbGASU. - SPb., 2011)

5. V. E. Gordienko (SPbGASU. - SPb., 2012)

6. V.M. Goritsky, J.Ind.civil eng. 9, 38-40 (2005)

7. V. E. Gordienko, J.Contr,.Diagn., 9, 27-29 (2008)

8. O. Bardišev J.World Appl. Sci., 23, $74-79$ (2013)

9. V. E. Gordienko (SPbGASU. - SPb., 2015).

10. V. E. Gordienko (SPbGASU. - SPb. 2018)

11. V. Gordienko, E,Gordienko, E. Smirnova, J.Appl.Sc.Eng.Techn., 11, 10, 1075-1083 (2015)

12. L.K. Gordienko (Moscow, Metallurgiya, 1973).

13. H.W. Hayden (1968)

14. Yu.M. Lakhtin (M.: Metallurgiya, 1979)

15. S.A. Saltykov (Moscow, Metallurgiya, 1970)

16. M.N. Bodyako (Minsk: Science and technology 1968) 